\title{
Proceeding
}

10th INSHS International Christmas Sport Scientific Conference, 4-5 December 2015. International Network of Sport and Health

Science. Szombathely, Hungary

\section{Motor imagery, perspective taking and gender differences: a VVIQ2-based study}

\author{
PIO ALFREDO DI TORE 1 , GAETANO RAIOLA², GAETANO ALTAVILLA ${ }^{2}$, SALVATORE BARBA $^{3}$, \\ SALVATORE PIGNATO ${ }^{4}$, MARIO LIPOMA ${ }^{4}$ \\ ${ }^{1}$ ISIS Corbino, Contursi Terme, Salerno, Italy \\ 2 Università degli Studi della Basilicata \\ 3 I.C. San Valentino Torio, Salerno, Italy \\ 4 Università Kore di Enna, Italy
}

\begin{abstract}
Scientific literature highlighted gender differences in spatial orientation. In particular, men and women differ in terms of the navigational processes they use in daily life. Scientific literature highlighted that women use analytical strategies while men tend to use holistic strategies. Furthermore, studies exploring gender differences in self-reported dream perspectives reported that women dream mainly in first person and men mainly in third person. This work used Vividness of Movement Imagery Questionnaire-2 to verify if gender differences in perspective taking last also in motor imagery practice. The aim of VVIQ2 questionnaire is to determine the vividness of movement imagery. In the VVIQ2, the image can be obtained watching oneself while performing the movement from an external point of view (External Visual Imagery), or from an internal point of view, as if you were looking out through your own eyes while performing the movement (Internal Visual Imagery). The Questionnaire was administered to students of Sports Sciences Degree from University of Salerno. Key words: VISUAL IMAGERY, GENDER DIFFERENCES, MOTOR PLANNING, COGNITIVE AND PERCEPTUAL SKILLS.
\end{abstract}

Corresponding author. Via Casa Leone 7, Salerno, Italy

E-mail: alfredo.ditore@gmail.com

10th INSHS International Christmas Sport Scientific Conference, 4-5 December 2015. International Network of Sport and

Health Science. Szombathely, Hungary.

JOURNAL OF HUMAN SPORT \& EXERCISE ISSN 1988-5202

(C) Faculty of Education. University of Alicante

doi:10.14198/jhse.2016.11.Proc1.13 


\section{INTRODUCTION}

Scientific literature highlighted gender differences in spatial orientation. In particular, men and women differ in terms of the navigational processes they use in daily life (Lambrey \& Berthoz, 2007).

According to Lawton, women use analytical strategies in spatial navigation, while men tend to use holistic strategies (Lawton, 2010).

Furthermore, studies exploring gender differences in self-reported dream perspectives reported that women dream mainly in first person and men mainly in third person (Soper, Rosenthal \& Milford, 1994).

This work used Vividness of Movement Imagery Questionnaire-2 to verify if gender differences in perspective taking last also in motor imagery practice. In this study, the self perception aspects (Raiola, 2015), physical self efficacy (Gomez et al., 2014) and motor control ones (Raiola, 2014), although they can explain the outcomes in different way, are not considered because the purpose is to strictly investigate just on different of gender.

\section{MATERIAL AND METHODS}

\section{Vividness of Movement Imagery Questionnaire-2}

The aim of this questionnaire is to determine the vividness of movement imagery. The items of the questionnaire are designed to bring certain images to mind. Users are asked to rate the vividness of each item by reference to the 5-point scale (Roberts, Callow, Hardy, Markland, \& Bringer, 2008).

The image aroused by each item might be:

Table 1. Image aroused by each item

Perfectly clear and as vivid (as normal vision or feel of movement) $\quad \ldots \ldots \ldots . \quad$ RATING 1

\begin{tabular}{llc}
\hline Clear and reasonably vivid & $\ldots \ldots \ldots$ & RATING 2 \\
Moderately clear and vivid & $\ldots \ldots . .$. & RATING 3 \\
Vague and dim & $\ldots \ldots . .$. & RATING 4 \\
No image at all, you only "know" that you are thinking of the skill & $\ldots \ldots .$. & RATING 5 \\
\hline
\end{tabular}

The first column is for an image obtained watching yourself performing the movement from an external point of view (External Visual Imagery). 
Table 2. Watching yourself performing the movement (External Visual Imagery)

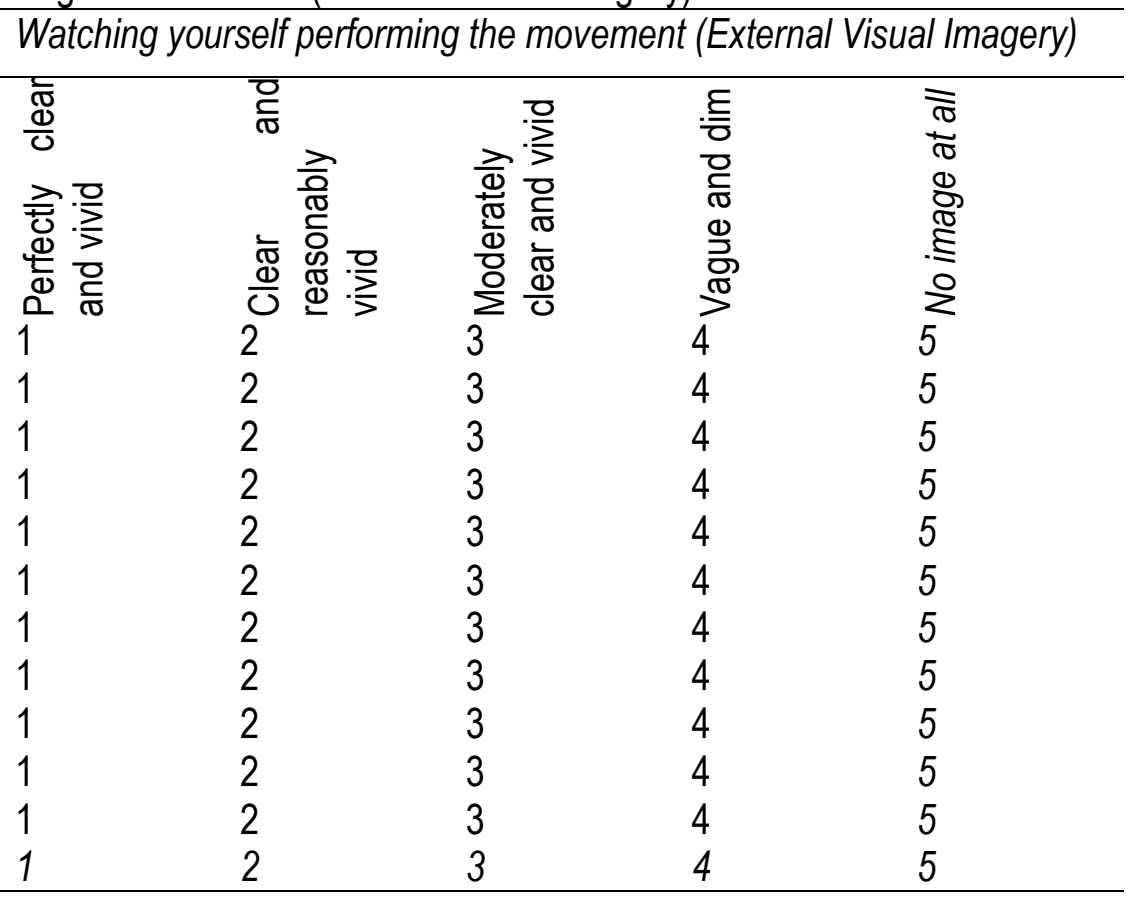

The second column is for an image obtained from an internal point of view, as if you were looking out through your own eyes whilst performing the movement (Internal Visual Imagery).

The third column is for an image obtained by feeling yourself do the movement (Kinaesthetic imagery).

Each score should range between 12 and 60 (as there are 12 items, with a score of 1 to 5 for each). The lower the score, the better the athlete is at using that particular imagery type. There is no "gold-standard" with regards to what score would indicate that an athlete is very skilled at a particular type of imagery.

VMIQ-2 authors suggest that if you are going to undertake an imagery intervention using a particular type of imagery (e.g., IVI) then the athlete should have a total IVI score of no more than 36 . This value corresponds to a moderate level of imagery ability (Roberts et al., 2008).

\section{RESULTS}

The Questionnaire was administered to students of Sports Sciences Degree from University of Salerno (15 males, 15 females).

Table 3. Questionnaire results

\begin{tabular}{cccc}
\hline EVI & f & IVI & f \\
$\mathbf{m}$ & 57 & $\mathbf{m}$ & 26 \\
14 & 40 & 20 \\
19 & 45 & 49 & 33 \\
54 & 47 & 44 & 27 \\
21 & 43 & 43 & 20 \\
52 & 59 & 44 & \\
\hline
\end{tabular}




\begin{tabular}{llll}
\hline 16 & 37 & 57 & 18 \\
47 & 39 & 52 & 24 \\
17 & 33 & 33 & 19 \\
14 & 26 & 32 & 22 \\
32 & 46 & 42 & 18 \\
60 & 23 & 54 & 31 \\
22 & 32 & 37 & 26 \\
14 & 32 & 37 & 24 \\
16 & 58 & 60 & 40 \\
45 & 47 & 32 & 39 \\
30 & 42 & 44 & 26 \\
\hline
\end{tabular}

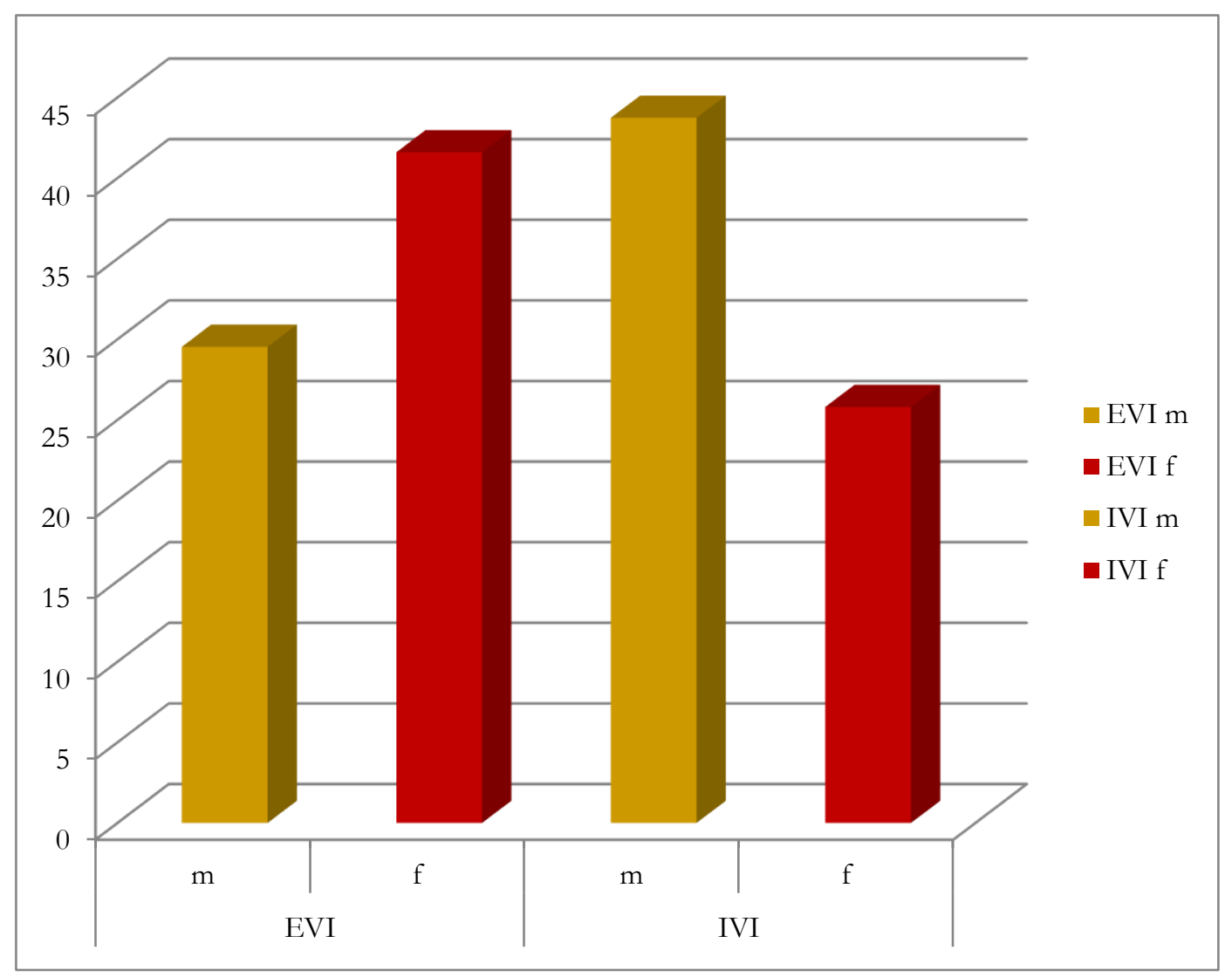

Figure 1. External Visual Imagery (EVI) and Internal Visual Imagery (IVI) for males and females

\section{DISCUSSION \& CONCLUSIONS}

The data analysis is still ongoing, however, in a first recognition, data presented seem to confirm a female preference for first-person perspective and a male preference for the third-person perspective. If confirmed, the data would suggest to develop gender-based strategies for developing imagery skills(Raiola, Scassillo, Parisi, \& Di Tore, 2013; Raiola, Tafuri, \& Gomez Paloma, 2014) in male athletes and female athletes. 
The results, given the small sample size, are certainly not be generalized, however, with the sole aim of this pilot study, results were considered encouraging by the project team, which decided to extend the screening.

\section{REFERENCES}

1. Lambrey, S., \& Berthoz, A. (2007). Gender differences in the use of external landmarks versus spatial representations updated by self-motion. Journal of integrative neuroscience, 6(03), 379-401.

2. Lawton, C. A. (2010). Gender, spatial abilities, and wayfinding Handbook of gender research in psychology (pp. 317-341): Springer.

3. Gomez Paloma F., Rio L., D'Anna C., (2014) Physical self-efficacy in women's artistic gymnastic between recreational and competitive level, Journal of Human Sport and Exercise 9.

4. Raiola G. (2015). Inclusion in sport dance and self perception, Sport Science, 81.

5. Raiola, G. (2014). Motor control and learning skills according to cognitive and ecological dynamic approach in a vision on behaviorism, cognitive, Gestalt and phenomenology theories . Mediterranean Journal of Social Sciences, 15(5), 504-506.

6. Raiola, G., Scassillo, I., Parisi, F., \& Di Tore, P. A. (2013). Motor imagery as a tool to enhance the didactics in physical education and artistic gymnastic. Journal of Human Sport and Exercise, 8(2). doi:10.4100/jhse.2012.8.Proc2.11

7. Raiola, G., Tafuri, D., \& Gomez Paloma, F. (2014). Physical activity and sport skills and Its relation to mind theory on motor control. Sport Science, 7(1), 52-56.

8. Rio L., Di Rubbo N., \& Gomez Paloma F., (2014) Natural acquisition of the second language through routine movements in children, Journal of Human Sport and Exercise vol. 91 supplement.

9. Roberts, R., Callow, N., Hardy, L., Markland, D., \& Bringer, J. (2008). Movement imagery ability: development and assessment of a revised version of the vividness of movement imagery questionnaire. J Sport Exerc Psychol, 30(2), 200-221.

10. Soper, B., Rosenthal, G. T., \& Milford, G. E. (1994). Gender differences in dream perspectives. Psychological reports, 74(1), 311-314. 